\title{
DENOMINAÇÕES DA INFÂNCIA: DO ANORMAL AO DEFICIENTE*
}

\author{
ERIC PLAISANCE*
}

\begin{abstract}
RESUMO: Que lugar pode ocupar o estudo da deficiência no quadro da sociologia da infância? Tal é a contribuição que gostaríamos de apresentar, analisando, ao mesmo tempo, a história da infância dita "deficiente" e as evoluçóes recentes, a partir de 1975, em matéria de escolarização. Ao mesmo tempo que damos descrições detalhadas dessas evoluções, procuramos pôr à prova duas hipóteses complementares: 1) A representação da criança portadora de "deficiência" é dominada pela representação da deficiência, mais do que pela representação da criança como criança, com suas particularidades eventuais?" 2) A alteridade "comum" da criança com relação ao adulto é redobrada no caso da criança deficiente e torna ainda mais ambíguas a enunciação e a aplicação, a seu respeito, da ideologia moderna dos direitos da criança. ${ }^{2}$
\end{abstract}

Palavras-chave: Criança deficiente. Direitos das crianças. Escolarização.

\section{DENOMINATIONS OF CHILDHOOD: FROM ABNORMALITY TO DISABILITY}

ABSTRACT: What place should be given to the studies on disability within the sociology of childhood? This is the contribution we would like to make through the analysis of both the history of the so-called "disabled" childhood and of the recent schooling evolutions, from 1975 onward. While giving detailed descriptions of such evolutions, we seek to test two additional hypotheses: 1) The representation of children with "disabilities" is dominated more by the representation of disability than by that of children, with its potential particularities. 2) Otherness, "common" to all children with regard to adults, is here doubled in the case of disabled children, which turns even more ambiguous stating and applying the modern ideology of the rights of children in their case.

Key words: Disabled children. Rights of children. Schooling.

\footnotetext{
* Tradução de Maria Fonseca, com revisão técnica de Ivany Pino.

** Professor da Universidade Paris 5 - René Descartes, Centro de Pesquisa sobre Laços Sociais (CERLIS).E-mail: ericplaisance@noos.fr
} 
Denominações e classificações: da criança anormal à criança deficiente

\section{Quais são as evoluções?}

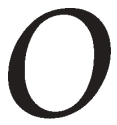

modelo de anormalidade e a denominação correlativa de "criança anormal" são cientificamente legitimados no fim do século XIX e no começo do século XX. As pesquisas de Monique Vial (1990) sobre a gênese da lei de 1909, relativa às escolas e classes de aperfeiçoamento destinadas às crianças ditas "retardadas", mostram que o modelo de anormalidade foi "importado" na escola por especialistas, "técnicos da infância anormal", conforme o vocabulário da autora. Não se trataria, pois, de modo nenhum, de um conceito elaborado pela escola. As reivindicações em proveito de classes especiais foram primeiramente feitas por esses técnicos, depois foram penetrando progressivamente os meios da educação, pelo menos no caso de certos responsáveis administrativos ou associativos. Tal interpretação, sustentada por uma documentação histórica sólida, opõe-se, é claro, ao esquema linear espontâneo que estabelece uma continuidade entre a lei sobre a obrigatoriedade do ensino primário (1882) e a lei sobre as classes de aperfeiçoamento (1909).

É verdade, no entanto, que a anormalidade e a criança anormal não recebem definições unívocas. Porém, no fim do século XIX, a atenção de uns e outros se volta para as situações escolares e para as crianças que não seriam "para a escola". Tanto os médicos quanto os psicopedagogos pretendem diagnosticar as "anormalidades escolares", para as quais eles fornecem, no mais das vezes, definições tautológicas. As crianças anormais são crianças que "em virtude da sua constituição física e intelectual se tornaram incapazes de aproveitar dos métodos comuns de instrução e de educação em vigor nas escolas públicas" (Binet \& Simon, 1907, p. 6-7). ${ }^{3}$

O modelo de inadaptação, formulado durante a Segunda Guerra Mundial (pelo "Conseil Technique pour l'Enfance Déficiente et en Danger Moral" de 1943), foi publicado na Liberação sob o nome de Lagache, e foi em seguida até os anos de 1960 largamente difundido. Para Michel Chauvière, "a causa da infância inadaptada progride de maneira decisiva num momento em que os valores da escola republicana são fortemente deslegitimados" (Chauvière \& Plaisance, 2000, p. 59). Além do mais, esse modelo valida as instâncias próximas da Saúde 
Pública (cujo ministério foi criado em 1920), que tem como perspectiva orientar as políticas no domínio da educação social, particularmente, no que concerne à infância dita "inadaptada". Sua definição pretende ser consensual: ela é suposta substituir todo um conjunto de denominações esparsas: crianças anormais, retardadas, deficientes, irregulares, esquizofrênicas, de rua, em perigo moral etc... "São inadaptados uma criança, um adolescente, ou de modo geral um jovem de menos de 21 anos cuja insuficiência das aptidóes ou cujos defeitos de caráter o colocam em conflito prolongado com a realidade e as exigências de seu entorno, realidade e exigências reclamadas pela idade e pelo meio social do jovem" (citado por Chauvière, 1980, p. 98). Uma tal definição apresenta um duplo aspecto. Por um lado, ela consagra o que Chauvière chama uma "naturalização" da infância inadaptada, pois o que aqui é posto em relevo são as carências individuais (inaptidões, defeitos de caráter). Por outro, ela póe em evidência o caráter interativo e mesmo conflitual da inadaptação.

O modelo da deficiência é consagrado pela lei de 1975, dita lei "de orientação em favor das pessoas deficientes". Na realidade, o relatório Bloch-Laîné de 1967 já o propunha, razão pela qual ele pode ser considerado um texto de transição entre o modelo de inadaptação e o de deficiência. Paradoxalmente, a lei de 1975 abstém-se de qualquer definição. Segundo os relatores de então, definir o conceito parecia-lhes totalmente impossível, visto as divergências de abordagens científicas existentes sobre a maneira de tratar o assunto e que, do ponto de vista deles, era necessário dar maior abertura possível sobre o futuro para evitar assim possíveis exclusões dos beneficiários da lei. A deficiência transforma-se em novo "sistema de referências da ação pública", suscetível de ser aplicado a todas as idades: "a deficiência é a lei".

Para a faixa de idade de 0 a 20 anos, as Comissões Regionais de Educação Especial (CDES) têm o poder de reconhecer ou não determinada criança como deficiente e, enquanto tal, elas podem atribuir eventualmente um subsídio de educação especial e orientar para um tipo dado de classe ou de estabelecimento. Uma lógica administrativa de referência entra em jogo. ${ }^{5}$ As orientaçôes efetuadas em função da "deficiência" são mais importantes que as referências à escolaridade normal, e, por conseguinte, mais importantes também que a referência à proximidade de idade com as crianças sem problema. 


\section{Quais as interpretações?}

A montante, quais são os atores em questão, que sustentam a legitimidade de tal denominação ou classificação? Os profissionais especializados cujo papel é de suma importância. Eles se apresentam como experts cuja qualificação é reconhecida para definir ou classificar. $\mathrm{O}$ saber científico é então requerido para substituir o saber espontâneo, e é esta legitimação pela ciência que é claramente reivindicada. Por essa razão o recuo histórico permite aí ver uma forte influência ideológica. Para Francine Muel (1975), "a institucionalização de um sistema de controle simbólico" sobre a infância com problemas, na virada do século XIX e do século XX, justifica-se por argumentos que têm sobretudo a ver com a defesa da ordem social. Além do que a classificação dos "anormais" delimita os interesses profissionais e os campos de ação. Binet \& Simon (1907) dizem, com uma elegância soberba, que convém eliminar (simbolicamente) as crianças das quais eles não precisarão se ocupar, as crianças com distúrbios neurológicos ou com deficiências mentais profundas que são diretamente mandadas para o campo médico: são as anormais de hospício ou de asilo. Para os autores, é inútil esperar qualquer eficiência de uma ação educativa feita em favor delas: tempo perdido e desperdício, pois só a creche se justifica. Em compensação eles se declaram competentes para definir, na qualidade de psicólogos, um outro grupo de anormais e as modalidades de ação conjuntas que requerem: trata-se das crianças retraçadas na própria escola, mas que não devem freqüentar as classes comuns. São as "anormais de escola”. Na realidade, os autores elaboraram uma "escala métrica da inteligência" para detectar na escola os retardados "perfectíveis", que são suscetíveis de freqüentar as classes precisamente chamadas de "aperfeiçoamento". Contrariamente aos "retardados de asilo", segundo a argumentação de Binet \& Simon, os retardados "perfectíveis" podem adquirir elementos da instrução primária, aprender certas normas sociais e, assim, serem socialmente utilizáveis mais tarde, no mercado de trabalho, no exercício de profissóes manuais.

Assim, detrás do discurso sobre o "bem" das crianças, correm na realidade, ao mesmo tempo, argumentos para a defesa da ordem social e ra-

N. da T.: "pro domo": expressão latina que significa "em seu favor, em defesa dos seus próprios interesses”; ver Aurélio Século XXI - O Dicionário da Língua Portuguesa, 5a imp., Editora Nova Fronteira, 1999, p. 1.643. 
zoados pro domo, ${ }^{*}$ cuja finalidade é convencer da pertinência do saber científico assim como da necessidade das intervençôes de tal ou tal profissional. Segundo Binet \& Simon, novamente, os professores do primário queixar-se-iam "energicamente" da presença de crianças retardadas em suas salas de aula: esses alunos pedem maior atenção e atrapalham o decorrer normal de uma aula. Ora, Monique Vial (1990a) não achou sequer rasto desse tipo de queixa que poderia ter gerado a reivindicação de classes especiais, pelo menos para o período 1882-1909. O que confirma perfeitamente o lugar que ocupam as "necessidades da escola" suspostas pelos profissionais para se apresentarem como indispensáveis. Do mesmo modo, Nathalie Bélanger (2002), que analisa a psicologia escolar na França após a Segunda Guerra Mundial, mostra devidamente que o argumento das "necessidades" da escola foi apresentado como uma justificação da presença dos psicólogos na escola, supostos para remediar os problemas levantados pela inadaptação infantil, retraçando por exemplo as crianças suscetíveis de serem orientadas para os dispositivos especiais.

A jusante, quais são as conseqüências das denominações? Que políticas estabelecer, que instituições criar, que práticas efetuar? Não se trata, pois, somente de uma questão de vocabulário, de uma valsa das etiquetas. Seguramente, há patologias que persistem, outras que mudam, mas o nosso olhar sabe detectar tal ou tal distúrbio. Neste sentido, as palavras fazem as coisas. As etiquetas "marcam", diz Mary Douglass (1999). Nomear e classificar é fazer existir, pois as representações a isso ligadas criam instituições e práticas. $\mathrm{O}$ trabalho assim em curso não releva mais somente uma lógica do saber mas também uma lógica que funda divisões de territórios. No começo do século $\mathrm{XX}$, os mais retardados vão para o asilo e os débeis para a escola (e as classes especiais). Por todo o período depois da Segunda Guerra Mundial (e em parte até hoje), faz-se a partilha entre os campos de competência do Ministério da Saúde e do Ministério da Educação, com a distinção de níveis de educabilidade, certas crianças sendo ainda consideradas "ineducáveis" por volta do fim dos anos de 1960 e relevando das instituições de saúde. A lógica das classificações é então uma lógica de experiências institucionais, mesmo de exclusões, de tal modo que o quociente intelectual, que só tem sentido no quadro de uma situação de exame clínico, tornou-se um critério de classificação de instituições especializadas definidas pelo QI. Os "esquemas classificatórios", segundo a expressão de Pierre Bourdieu (1979, p. 550), têm aqui como função principal a distinção e, no caso presente, a delimitação dos campos de ação. 
A análise sócio-histórica põe em relevo a pregnância da imagem do deficiente com relação à atenção dada ao estatuto da criança. É perfeitamente em razão dessa representação dominante que se deu primazia à ação educativa e às medidas escolares consideradas no quadro de referência de meios especializados limitados ao nível do ensino primário.

\section{Educação e escolarização}

Os debates sobre a educabilidade não são novos, eles se enraízam no século XVIII para as crianças deficientes sensoriais (surdas e cegas), e no século XIX para as deficientes intelectuais. Mas, a partir dos anos de 1980, tomaram um novo sentido pois concentraram-se em grande parte sobre a questão da integração escolar que perturba as representaçóes tradicionais.

\section{A obrigação educativa na lei de 1975 "em favor das pessoas deficientes"}

A lei enuncia que as crianças e os adolescentes deficientes sejam submetidos à "obrigação educativa”, quer seja sob a forma de uma educação comum quer seja sob a forma de uma educação especial. No momento da preparação da lei, foram feitas propostas em favor não da "obrigação educativa", mas da "obrigação escolar". Idas e vindas complicadas estenderam-se entre a Câmara dos Deputados e o Senado. Ao reter a obrigação educativa, o legislador punha ipso facto em valor o princípio da educabilidade de qualquer criança, quaisquer que fossem suas eventuais deficiências, e distanciava-se assim dos períodos ainda próximos em que se fazia a distinção entre as crianças "educáveis", as "semi-educáveis" e as "não-educáveis". No espírito dessa lei, e segundo seus defensores no governo da época, qualquer criança é, pois, declarada "educável”, mas qualquer criança não é necessariamente "escolarizável”.

\section{$\mathrm{O}$ direito à escolarização}

Apesar das medidas adotadas após a lei de 1975 (exatamente em 1982 e 1983) para favorecer a integração das crianças deficientes (mas também das que têm distúrbios da personalidade), numerosas críticas 
foram feitas sobre a fraca aplicação da lei: integraçôes escolares feitas "experimentalmente", sem verdadeira continuidade de ação, rejeição progressiva para os meios especializados à medida do desenvolvimento da escolaridade etc. Em 1999, houve uma "retomada" oficial da política de escolarização das crianças deficientes sob o título de "handiscol".

Essa "retomada" foi formulada sob os auspícios do direito, mais exatamente em termos de direito fundamental à escolarização para qualquer criança, quaisquer que sejam as deficiências ou as doenças que possam perturbar o seu desenvolvimento. A formulação mais vaga da lei de 1975 que se satisfazia da "obrigação educativa" se acha, pois, ultrapassada. Para precisar a necessidade da escolarização de crianças e adolescentes deficientes reteve-se uma formulação geminada: "a escolarização é um direito"; "acolher é um dever".

Começou-se então um processo de revisão da lei de 1975, primeiro com um grupo de visão em 2001-2002 sob o governo socialista (Assante, 2002), em seguida com o Parlamento em 2004. No projeto de lei "Para a igualdade dos direitos e das chances, a participação e a cidadania das pessoas deficientes" considerou-se a escolarização sob o título geral da acessibilidade. O serviço público de educação deve assegurar às crianças deficientes ou apresentando distúrbios de saúde que as tornam inválidas "uma formação escolar, superior ou profissional". Além disso, elas são inscritas na escola normal mais próxima de sua casa, com a possibilidade no entanto, em função das suas "necessidades particulares", de receberem uma formação nos estabelecimentos ou serviços médico-sociais. Além dessas precisóes a vir sobre a aplicação dessa nova lei, convém reter que a criança em situação de deficiência não é mais considerada somente educável, como em 1975, mas também escolarizável. O que coloca a questão das modalidades dessa escolarização, necessariamente diversificadas conforme os casos particulares. Mas as evoluções dos anos de 1980 e 1990 puseram em relevo o projeto individualizado, concebido como o meio pelo qual a trajetória de qualquer criança deficiente deve ser definida pelos atores envolvidos. Pôr em relevo o indivíduo na qualidade de indivíduo é, claro, uma orientação inteiramente moderna e que não é específica às crianças deficientes, mas essa orientação se opõe às representações tradicionais das crianças, apresentando um tipo ou outro de deficiência, como formando uma massa indistinta, somente identificada pelo fato de ser deficiente, em detrimento da pessoa. ${ }^{7}$ 


\section{Que direitos para crianças deficientes?}

Nas análises precedentes, foram privilegiados os pontos de vista normativos adotados pelos adultos sobre as crianças portadoras de deficiências. Outras maneiras de abordar o assunto são, claro, possíveis, ainda que, atualmente, bastante raras. No caso de algumas crianças, elas podem ir de encontro a dificuldades metodológicas ligadas seja à capacidade que essas crianças têm de compreensão, seja à capacidade delas de interação com o pesquisador. Mas sem dúvida podemos aprender muito com disciplinas e práticas, como as da psicanálise, que ampliam as representaçôes das crianças, do ponto de vista delas, numa relação de tipo clínico. Outros tipos de observaçóes foram experimentados, por exemplo observações sobre as interaçōes entre as crianças sãs e as crianças deficientes, ou sobre suas preferências recíprocas. ${ }^{8}$

Todavia a análise das representações das crianças portadoras de deficiências é interessante pois amplifica a das representações da criança em geral. Ela funciona como uma lente de aumento da questão proposta por pesquisadores de filosofia política a respeito do estatuto e dos direitos da criança. ${ }^{9}$ Segundo Alain Renaut (2002), a dinâmica democratizante e igualitária das sociedades modernas operou progressivamente uma aproximação de estatuto entre a criança e o adulto ocultando o critério da idade. As declaraçōes dos direitos da criança enunciaram, primeiro, direitos correspondentes, na realidade, às proteçōes concedidas pelo adulto (proteçôes físicas, por exemplo). Ora, as declaraçōes como as que foram feitas em 1989 nas Naçôes Unidas introduziram uma ruptura clara nas representações da criança. Não se trata mais somente de direitos-proteção mas de direitos-liberdade (opinião, expressão, reunião...). Entramos então numa fase, ao mesmo tempo, nova e contraditória das nossas relações com a criança. Por um lado, os direitos-proteção referem a uma visão comumente compartilhada e em certo sentido tradicional dessas relaçōes, por outro, a aplicação estrita dos direitos-liberdade mina a relação de autoridade do adulto para com a criança, isto é, o processo de socialização definido por Durkheim como relação vertical das geraçôes adultas para com as mais jovens "que não são ainda amadurecidas para a vida social". Para Alain Renaut, os dois tipos de direitos deveriam ser articulados para se evitar os excessos de uns e outros. Os direitos-proteção viriam impor seus limites aos direitos-liberdade e, reciprocamente, os direitos-liberdade viriam contra- 
balançar as proteções que poderiam pôr fim a qualquer processo de autonomização das crianças.

A problemática dos direitos das crianças, oriunda da filosofia política, oferece pistas de interpretação dos dados precedentes, assim como chaves para a análise dos debates em curso sobre os "direitos" das crianças portadoras de deficiências.

\section{Propostas à maneira de conclusões}

Proposta 1: A história das representações da deficiência (denominações e classificações, assim como suas conseqüências sobre as instituições e as práticas) é caracterizada pela assimilação da criança portadora de deficiências a uma criança mais jovem ou a uma criança peada no seu desenvolvimento. Daí vem a preeminência do critério da deficiência em detrimento do critério da idade cronológica.

Comentários:

- O caso da debilidade mental é revelador dessa assimilação. A criança débil foi considerada, nos trabalhos clássicos de Binet \& Simon no começo do século XX, uma criança cuja idade mental não correspondia à sua idade cronológica. ${ }^{10}$ Somente trabalhos dos anos de 1960 tentaram delimitar as especificidades da debilidade, evitando reduzi-la a uma infância mais tenra: trabalhos de René Zazzo sobre a estrutura heterocrônica** da debilidade, trabalhos dos psicanalistas sobre as estruturas da personalidade, sobre os processos de debilização etc. (por exemplo, Roger Mises, Maud Mannoni, apesar das diferenças entre as escolas desses psicanalistas).

- A restrição ao ensino primário do ensino destinado às crianças portadoras de deficiências traduziu de modo significativo essa valorização da deficiência suposta de acarretar uma impossibilidade de acesso a níveis superiores de escolaridade, qualquer que fosse a idade das crianças e quaisquer que fossem os tipos de deficiência (incluídas as deficiências motoras, visuais, auditivas etc...).

\footnotetext{
** N. da T.: termo da psicologia cognitiva.
} 
Proposta 2: A evolução das representações em favor da interação escolar das crianças portadoras de deficiências, tanto quanto a aplicação do direito fundamental à escolarização para todos, em benefício delas, constituiu uma revalorização do estatuto da criança portadora de deficiências como criança, em detrimento do critério exclusivo da deficiência.

\section{Comentários:}

- A escolarização das crianças portadoras de deficiências é considerada, a partir do fim dos anos de 1990, a aplicação lógica, em favor delas, do direito à escolarização (e não mais somente à educação) para todos.

- As medidas de integração escolar, formuladas ofcialmente desde o começo dos anos de 1980, engrenam um processo de ajustamento da escolarização das crianças portadoras de deficiências à escolarização ordinária e, conseqüentemente, aos níveis de idade correspondentes. A extensão da escolarização das crianças portadoras de deficiências (compreendendo as deficiências mentais) ao segundo grau, oficialmente anunciada em 2003, é característica dessa evolução em favor do critério de idade, mesmo se modalidades específicas são previstas (por exemplo, as Unidades Pedagógicas de Integração nos colégios e liceus).

Proposta 3: A evolução das representações em favor da aplicação da bipolaridade dos direitos da criança em geral às crianças portadoras de deficiências gera uma dupla dificuldade: por um lado, a da alteridade "ordinária" da criança com relação ao adulto, por outro, a da especificidade da deficiência.

\section{Comentários:}

- A evolução precedentemente constatada em favor da revalorização do critério da idade aproxima a criança portadora de deficiências da criança "ordinária", fato ao qual se ajunta o processo contemporâneo de aproximação entre a criança e o adulto, na formulação moderna dos direitos da criança. Com efeito, ela supóe que se leve menos em conta o critério da idade para uma assimilação relativa criança-adulto.

- A enunciação e a aplicação da bipolaridade dos direitos da criança (direitos-proteção e direitos-liberdade) são ainda bem pouco aplicadas às crianças portadoras de deficiências. Estas são vistas 
como tendo de se beneficiar necessariamente dos "direitos-proteção", que são, na realidade, obrigações de proteção dos adultos com relação a elas, mas não como pessoas que devem ter acesso aos "direitos-liberdade". Muitas medidas são ainda tomadas "para o bem delas", mas entravam precisamente seus "direitos-liberdade", como os direitos à expressão, à autonomia, à sexualidade.

Proposta 4: A evolução das representaçôes das crianças portadoras de deficiências torna ainda mais notável a questão da alteridade criança-adulto, nessa tensão entre proteção e liberdade. Ela atua como um revelador das dificultades de aplicação dos direitos da criança em geral. Neste sentido, a deficiência reitera e põe em evidência as aporias contemporâneas dos direitos da criança.

\section{Recebido em novembro de 2004 e aprovado em março de 2005.}

\section{Notas}

1. Foi Monique Vial, de quem somos devedores, que formulou essa hipótese a respeito da história da normalidade, hipótese que estendemos às épocas contemporâneas, que utilizam o vocabulário da "deficiência". Segundo Monique Vial, que analisa a situação no fim de século XIX e no começo do século XX, "as crianças anormais são vistas mais como anormais que como crianças. O futuro delas, de adolescentes primeiro, depois de adultos, é mais preocupante que a infância. O discurso científico não faz distinções de idade" (Vial, 1998, p. 347).

2. As análises de Alain Renaut (2002) constituem aqui um pano de fundo de referência importante, pois elas colocam claramente a questão da aplicação dos direitos às crianças.

3. Uma definição semelhante foi publicada em 1911, sob a assinatura de Gustave Baguer, no "Nouveau dictionnaire de pédagogie et d'instruction primaire" de Ferdinand Buisson: essas crianças "não podem ser instruídas suficientemente pelos métodos pedagógicos comumente empregados para os alunos providos de todos os sentidos e dotados de uma inteligência média" (Buisson, 1911, artigo "anormaux"). As primeiras edições do dicionário de Ferdinand Buisson (anos 1882 e seguintes), verdadeira bíblia da escola republicana do fim século XIX, não tinham artigo nenhum sobre a criança anormal. $\mathrm{O}$ que confirma a penetração lenta e tardia do modelo de anormalidade nos meios pedagógicos.

4. É o titulo de uma parte do livro coordenado por Catherine Barral e colaboradores (2000). Michel Chauvière retém a expressão "sistema de referências da ação pública", que designa classicamente "o conjunto das normas prescritivas (modos de designação dos objetivos, critérios de escolha...) que dão sentido a um programa de ação governamental em um dado setor" (1980, p. 245).

5. Observações semelhantes são partilhadas por Robert Castel (1981).

6. Circular de 19 de novembro de 1999. O mesmo texto ajunta: "Cada escola, cada colégio, cada liceu tem por vocação acolher, sem discriminação, as crianças e os adolescentes deficientes cuja família solicite a integração escolar. Só se transgredirá essa regra geral se, depois de

Educ. Soc., Campinas, vol. 26, n. 91, p. 405-417, Maio/Ago. 2005

Disponível em <http://www.cedes.unicamp.br> 
um exame pormenorizado da situação, dificuldades importantes tornam, objetivamente, essa integração impossível ou por demais exigente para o aluno". Uma tal formulação é retomada integralmente numa circular mais recente, datada de 30 de abril de 2002.

7. Para François de Singly (2004), o movimento de individualização toca as crianças, no período que ele chama de "segunda modernidade".

8. Marie Françoise Berthe-Deneux \& Véronique Léoni, em Chauvière \& Plaisance (2000), e Cornelia Schneider, pesquisa em curso sobre as preferências recíprocas segundo a técnica dos sociogramas.

9. Retorno a Sarah...

10. René Zazzo comenta assim a história da escala métrica da inteligência a partir dos trabalhos de Binet \& Simon: "A inteligência é definida pela sua gênese na criança, e seus graus correspondem às idades sucessivas de desenvolvimento mental. A debilidade é um atraso desse desenvolvimento... a criança débil é assimilada a uma criança mais jovem” (Zazzo, Gilly \& Verba-Rad, 1967, p. 15).

\section{Referências bibliográficas}

ASSANTE, V. et al. Mission d'étude en vue de la révision de la loi d'orientation du 30 juin 1975 en faveur des personnes handicapées; rapport remis à Ségolène Royal, ministre déléguée à la Famille, à l'Enfance et aux Personnes Handicapées. Paris: Ministère délégué à la famille, à l'enface et aux personnes handicapées, 2002.

BARRAL, C. et al. (Ed.). Linstitution du handicap: le rôle des associations, XIXe-XXe siècles. Rennes: Presses Universitaires de Rennes, 2000.

BELANGER, N. De la psychologie scolaire à la politique de l'enfance inadaptée. Paris: CTNERHI, 2002.

BINET, A.; SIMON, T. Les enfants anormaux: guide pour l'admission des enfants anormaux dans les classes de perfectionnement. Paris: Colin, 1907.

BOURDIEU, P. La distinction: critique sociale du jugement. Paris: Minuit, 1979.

CASTEL, R. La gestion des risques. Paris: Minuit, 1981.

CHAUVIÈRE, M. Enfance inadaptée: l'héritage de Vichy. Paris: Ouvrières, 1980.

CHAUVIĖRE, M.; PLAISANCE, E. (Ed.). L'école face aux handicaps: education spéciale ou éducation intégrative? Paris: Presses Universitaires de France, 2000. 
DOUGLASS, M. Comment pensent les institutions. Paris: La Découverte, 1999.

MUEL, F. L'école obligatoire et l'invention de l'enfance anormale. Actes de la Recherche en Sciences Sociales, Paris, n. 1, p. 60-74, 1975.

PLAISANCE, E.; GARDOU, C. Présentation du dossier "Situations de handicap et institution scolaire". Revue Française de Pédagogie, Paris, n. 134, p. 5-13, 2001.

RENAUT, A. La libération des enfants. Paris: Bayard et Calmann-Levy, 2002

SINGLY, F. (Ed.). Enfants - adultes: vers une égalité de statuts? Paris: Encyclopaedia Universalis, 2004.

VIAL, M. Les enfants anormaux à l'école: aux origines de l'éducation spécialisée, 1882-1909. Paris: Colin, 1990.

VIAL, M. Enfants handicapés du XIXe au XXe siècle. In: BECCHI, E.; Julia, D. (Ed.). Histoire de l'enfance en Occident. Paris: Seuil, 1998. t.2., p. 331-357.

ZAZZO, R.; GILLY, M.; VERBA-RAD, M. Nouvelle échelle métrique de l'intelligence. Paris: Colin, 1967. v.1 